\title{
Los juegos olímpicos en Río de Janeiro y las leyes de excepción
}

\author{
The Rio de Janeiro Olympic Games \\ and the Exception Laws
}

\section{Claudio Oliveira de Carvalho*}

Raoni Andrade Rodrigues**

\begin{abstract}
SUMARIO: I. Introducción. II. La ciudad como mercancía, empresa y patria. III. La ley como instrumento de expoliación urbana y de segregación socioespacial. IV. Los Juegos Olímpicos como vector de revitalización y desarrollo urbano. V. Las leyes de excepción que amparan a la realización del megaevento olímpico. VI. El Acto Olímpico Federal y el Decreto Municipal 30.379/2009. VII. Legado ¿para quién? Formulando consideraciones finales. VIII. Bibliografía.
\end{abstract}

* Abogado. Doctor en Desarrollo Regional y Planificación Urbana; maestro en Derecho; docente en la Universidad Estadual del Suroeste de Bahia (UESB). Integrante del Núcleo de Asesoría Jurídica Alternativa (NAJA) y coordinador del Grupo de Pesquisa en Derecho Ambiental, Urbanístico, Agrario y Movimientos Sociales de la Universidad del Suroeste de Bahia (UESB).E-mail: ccarvalho@uesb.edu.br.

** Abogado. Especialista en Derecho Tributario; miembro del Grupo de Pesquisa en Derecho Ambiental, Urbanístico, Agrario y Movimientos Sociales de la Universidad del Suroeste de Bahia (UESB). E-mail: raoniarodrigues@gmail.com.

Artículo recibido el 20 de junio de 2016 Aprobado para publicación el 22 de septiembre de 2016 
Resumen: Incluso antes de su finalización, los Juegos Olímpicos 2016 en Río han traído muchas contradicciones y ambigüedades en su ciudad anfitriona. Mientras las promesas de legados grandiosos son repercutidas desde el día en que se anunció el megaevento deportivo, Río de Janeiro se ha convertido en un escenario de la privatización del espacio urbano y de la segregación socioespacial. Este estudio busca establecer cuánto tiene de influencia esa lógica elitizadora y depredadora de la producción de la ciudad en la elaboración de leyes de excepción que eclipsan a las conquistas legislativas, y cómo la política urbana relacionada al derecho a la ciudad termina siendo suprimida en este contexto de los megaeventos.

Palabras claves: Juegos Olímpicos Río 2016, leyes de excepción, política urbana, derecho a la ciudad, megaeventos.

ABSTRACT: Even before its completion, the Rio 2016 Olympic Games have brought many contradictions and ambiguities to their host city. While the promises of magnificent legacies have repercussions since the day that the massive sports event was announced, Rio de Janeiro has become an urban space of privatization and socio-spatial segregation. This study seeks to establish how this logic of elitism and predation of production in the city influence the creation of exception laws that eclipse legislative achievements, and how urban policy related to the Right to the City ends up being suppressed in this context of mega-events.

Key words: Rio 2016 Olympic Games, exception laws, urban policy, Right to the City, mega-events.

RÉSUMÉ: Même avant qu'ils se terminent, les Jeux Olympiques de Rio 2016 ont suscité beaucoup de questions et d'ambiguïtés dans la ville hôte. Pendant que les promesses d'énormes bénéfices étaient assénées depuis le jour de l'annonce du méga-événement sportif, Rio de Janeiro se transformait en laboratoire de la privatisation de l'espace urbain et de la ségrégation socio-spatiale. Cette étude cherche à mesurer l'influence de cette logique appliquée à la production urbaine, logique élitiste et déprédatrice, sur la création de lois qui éclipsent les conquêtes juridiques et s'interroge sur le fait que les politiques urbaines en matière de «droit de la ville» finissent toujours par être supprimées dès lors qu'un méga-événement se présente.

Mots-clés: Jeux Olympiques de Rio 2016, lois d'exception, politique urbaine, droit de la ville, méga-événement. 
Esta revista forma parte del acervo de la Biblioteca Jurídica Virtual del Instituto de Investigaciones Jurídicas de la UNAM

\section{INTRODUCCIÓN}

La elección de Río de Janeiro como sede de los Juegos Olímpicos de 2016 fue recibida con gran entusiasmo por varios sectores de la sociedad brasileña. De hecho, para una ciudad en la periferia del capitalismo, la realización de un gran evento de esta magnitud no se limita al periodo de preparación para las festividades deportivas que congregan a personas y naciones. Por su notable capacidad de absorber recursos materiales y simbólicos, ${ }^{1}$ los Juegos Olímpicos son vistos como un medio para superar los males que han sido desde hace mucho tiempo enraizados en la capital carioca, en ámbitos tales como la movilidad urbana, la seguridad y las finanzas públicas, la vivienda, entre muchos otros.

El proyecto titulado Ciudad Olímpica está lleno de sentimientos y valores relacionados con el diseño de una metrópoli más moderna, limpia y segura, capaz de proporcionar más dignidad y calidad de vida para sus habitantes. De acuerdo con el Comité Popular de la Copa y de los Juegos Olímpicos en Río de Janeiro, ${ }^{2}$ este proyecto anuncia que será el fin de la "ciudad dividida”, en la medida en que la población se integrará hacia objetivos comunes; sin embargo, lo que resulta es todo lo contrario: son conocidos los procesos de exclusión social, las violaciones de los derechos humanos y las intervenciones urbanas ilegales y sin mayores vocaciones a la eficacia.

Esta desigualdad se puede demostrar en los números. Se estima que en Brasil los megaeventos (la Copa del Mundo en 2014 y los Juegos Olímpicos en 2016) provocaron la remoción de unas 170,000 personas en todo el país. ${ }^{3}$ Río de Janeiro, como la única sede Olímpica, es la ciudad más afectada. En 2015, el Comité Popular de la Copa y de los Juegos Olímpicos en Río de Janeiro estimaba que 4,120 familias se habían retirado y que 2,486

1 Oliveira, Nelma G., Força de Lei: rupturas e realinhamentos institucionais na busca do "sonho olímpico”carioca, Río de Janeiro, Actas del XIV Encontro Nacional da ANPUR, 2011, pp. 1-20.

Comité Popular de la Copa y de los Juegos Olímpicos en Río de Janeiro, Megaeventos e Violações dos Direitos Humanos no Rio de Janeiro, 2015, disponible en: https: / /br.boell.org/sites / default/files/dossiecomiterio2015_-_portugues.pdf (fecha de consulta: 15 de febrero de 2016).

3 Global Brasil, Remoções forçadas para Copa e Olimpíadas no Brasil serão tratadas em sessão do Conselho de Direitos Humanos da ONU, 2013, disponible en: http: / /global.org.br/programas / remocoes-forcadas-para-copa-e-olimpiadas-no-brasil-serao-tratadas-em-sessao-do-conselho-de-direitos-humanos-da-onu/ (fecha de consulta: 15 de febrero de 2016. 
Esta revista forma parte del acervo de la Biblioteca Jurídica Virtual del Instituto de Investigaciones Jurídicas de la UNAM

permanecían amenazadas por las obras directamente relacionadas con megaeventos deportivos. ${ }^{4}$

Así como la Copa del Mundo 2014, los Juegos Olímpicos de 2016 son la expresión de un proyecto de revitalización urbana de la ciudad de Río de Janeiro, que se basa en “...un modelo de gobierno neoliberal emprendedor, con el apoyo de una coalición de intereses económicos, políticos y sociales". En una coalición de intereses entre el Estado y el sector privado, por ejemplo, las políticas públicas están subordinadas a la lógica del negocio inmobiliario, financiero y turístico. A su vez, la planificación urbana, específicamente, en lugar de concentrarse en la realización del derecho a la ciudad, de la justicia social y de la calidad de vida urbana, se convierte en instrumento de elitización y mercantilización de la ciudad.

La actual discusión tiene muchas implicaciones legales, por dos motivos principales: en primer lugar, se violan los más fundamentales derechos humanos en nombre de la realización del evento; en segundo lugar, la propia legislación se deforma, con el fin de adecuar la ciudad a los Juegos.

Esta última información debe aclararse. Para que una ciudad sea capaz de acoger los Juegos Olímpicos, necesita estar sujeta a las diversas exigencias del Comité Olímpico Internacional (COI). En nuestro caso, muchos de estos requisitos están en conflicto con el sistema jurídico brasileño, ya que violan los derechos más básicos de la población, como la vivienda, la libre circulación, la libre competencia, la participación democrática en la gestión de su ciudad, entre otros. Así que, dada esta contradicción, es necesario crear algunas leyes especiales a nivel municipal y federal para que se acojan los Juegos. Dos importantes leyes creadas para cumplir las expectativas del COI fueron el Decreto Municipal num. 30.379, del 1o. de enero de 2009, ${ }^{6}$ y la ley federal conocida como Acto Olímpico. ${ }^{7}$

4 Comité Popular de la Copa y de los Juegos Olímpicos en Río de Janeiro, op. cit.

5 Castro, Demian et al., "O Projeto Olímpico da Cidade do Rio de Janeiro: reflexões sobre os impactos dos megaeventos esportivos na perspectiva do direito à cidade”, en Santos Junior, Orlando et al., Brasil: os impactos da Copa do Mundo 2014 e das Olimpíadas 2016, E-papers, Río de Janeiro, 2015, p. 409 (traducción propia).

6 Río de Janeiro (Municipio), Decreto no. 30.379, de 1o. de janeiro de 2009. Dispõe sobre medidas a serem adotadas pelo Município do Rio de Janeiro para a realização dos Jogos Olímpicos e Paraolímpicos Rio 2016, na cidade do Rio de Janeiro, 2009, disponible en: http: / wpro.rio.rj.gov. br/decretosmunicipais/ (fecha de consulta: 21 de diciembre de 2015).

7 Brasil, Lei no. 12.035, de 1o. de outubro de 2009. Institui o Ato Olímpico, no âmbito da administração pública federal, com a finalidade de assegurar garantias à candidatura da cidade do Rio de Janeiro 
Esta revista forma parte del acervo de la Biblioteca Jurídica Virtual del Instituto de Investigaciones Jurídicas de la UNAM

Cualquier breve examen de la legislación antes citada permite observar cómo el Estado y la ley que guía sus actividades se convierten en promotores no sólo de los requisitos del COI, sino también de los intereses financieros de una serie de agentes privados, que son llamados a participar de la "fiesta olímpica".

Hay que indagar si la preparación para el megaevento impone nuevos paradigmas en la política urbana, para acercarla de los intereses del mercado y alejarla de los deseos de la población, o si, en cambio, se trataría de un periodo en el que los elementos existentes se intensifican y se propagan de manera más visible. Este estudio intenta contribuir a contestar estas cuestiones, a partir de un análisis de las leyes de emergencia establecidas para apoyar los Juegos Olímpicos y de la violación de los derechos humanos contenidos en estas leyes desde hace algún tiempo en el país. Se busca identificar, a partir de ello, los principales impactos de las intervenciones urbanas propuestas en el proyecto olímpico en Río de Janeiro, desde el punto de vista del derecho a la ciudad.

\section{LA CIUDAD COMO MERCANCÍA, EMPRESA Y PATRIA}

El megaevento olímpico ha dado mayor visibilidad e intensidad a las características más llamativas presentes en la ciudad contemporánea: la metrópoli que combina los aspectos de mercancía, de empresa y de patria. Carlos Vainer $^{8}$ (2001), defensor de ese punto de vista, explica que, si bien los problemas urbanos en el pasado estaban relacionados con la organización de un espacio cada vez más poblado, los problemas contemporáneos se originan de un escenario mundial con una alta competitividad entre las ciudades.

Ahora bien, ¿por qué compiten, precisamente? Por las inversiones, por la tecnología, por las sedes de las empresas, por los grandes eventos, por los turistas. Así como la globalización originó un ambiente en el que empresas de diferentes naciones compiten para atraer a los consumidores en todo el

a sede dos Jogos Olímpicos e Paraolímpicos de 2016 e de estabelecer regras especiais para a sua realização, condicionada a aplicação desta Lei à confirmação da escolha da referida cidade pelo Comitê Olímpico Internacional, 2009, disponible en: http: / /www.planalto.gov.br/ccivil_03/_ato2007-2010/2009/ lei/112035.htm (fecha de consulta: 15 de diciembre de 2015).

8 Vainer, Carlos B., "Pátria, empresa e mercado", en Arantes, Otília et al., A cidade do pensamento único: desmanchando consensos, Petrópolis, Vozes, 2001. 
Esta revista forma parte del acervo de la Biblioteca Jurídica Virtual del Instituto de Investigaciones Jurídicas de la UNAM

mundo, la misma globalización ha convertido las ciudades en severas rivales por cada centavo del inmenso capital que hoy circula alrededor del planeta.

La ciudad como mercancía puede representar una de las consecuencias más graves, según lo demuestra Henry Lefebvre en su obra El derecho a la ciudad. De acuerdo con el autor francés, la ciudad, que siempre se ha caracterizado por ser un lugar de consumo, también ha asumido la identidad de consumo del lugar. ${ }^{9}$ En esta lógica, los espacios urbanos se negocian a cambio de una mejor posición de la ciudad en el mercado mundial.

El alcalde de una ciudad a veces asume las características más de un vendedor que de un gestor público. Es común ver a los alcaldes viajando a otros estados o países proponiendo ventajas a todos los que demuestren interés en invertir en sus ciudades. Es digno de observación que los beneficios a menudo no se limitan a los aspectos fiscal y político, sino también se refieren a promesas de grandes reformulaciones urbanas, capaces de hacer la ciudad más receptiva a las inversiones, a los megaeventos o a los turistas.

La ciudad en su papel de empresa también crea preguntas delicadas. Se dice que las ciudades de hoy están inmersas en un mercado internacional altamente competitivo y deben actuar como auténticas empresas, con mecanismos para la toma de decisiones ágiles y capaces de adaptarse a un entorno que cambia rápidamente.

La introducción de un esquema de gobierno corporativo niega radicalmente la ciudad como espacio político. Los requisitos de adecuación al mercado internacional y la búsqueda por inversiones, sedes de empresas multinacionales, eventos y turistas a menudo tienen primacía frente a los mecanismos de participación popular. Según las palabras de Carlos Vainer: ${ }^{10}$ “...[En las ciudades-empresas] no se eligen dirigentes, ni son discutidos objetivos; tampoco hay tiempo y condiciones para reflexionar sobre los valores, la filosofía o las utopías. En la empresa reina el pragmatismo, el realismo, el sentido práctico; y productivización es la única ley”.

La noción de una crisis constante, que es la marca del neoliberalismo económico, contribuye a la creación de mecanismos de gobierno corporativo. La crisis lleva necesariamente a la necesidad de apaciguar las diferencias internas en nombre de la supervivencia de la ciudad. Se renuncia a la política institucional, a partir de un consenso construido sobre un escenario de caos inminente.

9 Lefebvre, Henri, El derecho a la ciudad, Barcelona, Península, 1978.

10 Vainer, Carlos B., op. cit., p. 91 (traducción propia). 
Esta revista forma parte del acervo de la Biblioteca Jurídica Virtual del Instituto de Investigaciones Jurídicas de la UNAM

No menos grave es la noción de patriotismo de la ciudad: con el fin de buscar el apoyo de la gente para megaproyectos dotados de gran participación privada, la ciudad se convierte en una pequena patria. Surgen concepciones como el orgullo por la cultura local, el aprecio por el pasado histórico y por los proyectos futuros. En esta nación de miniatura, los habitantes adquieren la voluntad colectiva para contribuir al desarrollo local.

Está claro que el patriotismo de la ciudad es otro factor atenuante en la política, pues el discurso patriótico busca artificializar una unión de todas las personas en nombre de la superación de los problemas urbanos. Según esta propuesta se produce un mayor consenso capaz de legitimar las asociaciones entre los sectores público y privado, con el objetivo de invertir las prioridades en nombre del éxito internacional. Por lo tanto, se niegan las diferencias naturales que caracterizan la vida urbana y se agrava la segregación socioespacial desmesurada que se difunde a través de los paisajes de las ciudades brasileñas. Cuanto más amor a la bandera de la ciudad, que ondea en mástiles cada vez más realzados, mayor es la ceguera con respecto a los problemas que afectan a la población.

El proyecto olímpico de Río de Janeiro muestra perfectamente cómo una ciudad puede ejercer los papeles de empresa, de patria y de mercado. La necesidad de abordar la situación de crisis interna y la presión de la competencia externa ha originado discursos en los que uno puede vislumbrar los elementos teóricos sistematizados por Carlos Vainer. De acuerdo con las justificaciones de los organizadores del Comité Olímpico Internacional, de los representantes del gobierno y de la comunidad empresarial que participa de alguna manera en la ejecución del proyecto, el evento deportivo internacional traerá numerosos beneficios a la capital de Río, ya que proporcionará una visibilidad global nunca antes concedida a la ciudad, además de la gran promesa del amplio legado urbano.

Para hacer frente a las complejidades de un mundo globalizado, la ideología mercantil sugiere (o impone) la creación de mecanismos más flexibles de gestión urbana. La competencia externa y la crisis que surge internamente, de acuerdo con esta perspectiva, requieren acciones gubernamentales más rápidas. No hay tiempo suficiente para elaborar políticamente las soluciones, para crear consenso, para planificar de manera multifocal. La ciudad, como espacio político por excelencia, se muere.

Una de las consecuencias más profundas de este escenario es la creación de leyes que ofrecen ventajas a las empresas que participan en la implemen- 
Esta revista forma parte del acervo de la Biblioteca Jurídica Virtual del Instituto de Investigaciones Jurídicas de la UNAM

tación de megaeventos. En el contexto de los Juegos Olímpicos de Río de Janeiro, esa tesis se puede demostrar a través del Decreto Municipal núm. 30.379/2009 y del Acto Olímpico federal. Tales documentos legales serán analizados con mayor detalle más adelante.

\section{LA LEY COMO INSTRUMENTO DE EXPOLIACIÓN URBANA Y DE SEGREGACIÓN SOCIOESPACIAL}

Históricamente, la ley era una herramienta sutil de la segregación urbana, y se habla de sutileza por el hecho de que este efecto funesto ocurre bajo una justificación de cierta manera convincente, vinculada a la estética urbana, al saneamiento, a la mejora de la movilidad y de la seguridad pública, a la revitalización de elementos históricos y al crecimiento competitivo de la ciudad en el escenario mundial.

Henry Lefebvre ${ }^{11}$ justifica de manera muy simple: en un país que se dice democrático, la segregación no se puede defender de forma explícita, por lo que hay un discurso humanista que suele justificar las medidas impopulares. Básicamente, lo que hace la ley es la promoción de un pacto entre las acciones de planificación urbana del Estado y las actividades lucrativas de las empresas.

De forma sumamente realista y precisa, Raquel Rolnik ${ }^{12}$ afirma que “...además de regular eficazmente la producción de la ciudad, la legislación urbana actúa como un marco delimitador de las fronteras del poder" (traducción propia). Surgen territorios dentro y fuera de la ley, así como la división entre los espacios en los que se vive plenamente la ciudadanía y otros en los que se violan constantemente los derechos humanos.

Puesto que la ley de urbanismo es un importante delimitador de los derechos humanos, movimientos sociales vinculados a la causa de la reforma urbana trataron de intervenir en la elaboración legislativa, a fin de que se concibieran ciudades más democráticas. Los artículos 182 y 183 de la Constitución Federal brasileña de 1988, junto con el Estatuto de la Ciudad de 2001, son ejemplos de logros jurídicos de los movimientos sociales.

11 Lefebvre, Henry, O direito à cidade, San Pablo, Centauro, 2001.

12 Rolnik, Raquel, A cidade e a lei: legislação, política urbana e territórios na cidade de San Pablo, San Pablo, Studio Nobel/Fapesp, 1997, p. 13. 
Desde entonces, Brasil tiene una base legal llena de instrumentos administrativos y legales con el potencial para superar muchas condiciones críticas experimentadas en sus más de 5,500 ciudades.

No obstante, es necesario hacer hincapié en que, por otro lado, el orden jurídico-urbanístico de Brasil se encuentra marcado por numerosas limitaciones en su eficacia: la mayoría de los instrumentos positivizada a nivel federal no ha sido regulada por los municipios y no se puede aplicar; al mismo tiempo, parte del marco regulatorio sigue ignorado, sea por el Poder Ejecutivo, que se omite de proporcionar políticas públicas urbanas de calidad, o por el Poder Judicial, que aún carece de una sólida jurisprudencia más acorde con los paradigmas del derecho a la ciudad, porque abogan, casi siempre, por la defensa de la propiedad privada (incluso cuando este derecho no tiene en cuenta su función social).

También hay un problema adicional con respecto a la eficacia del orden jurídico-urbanístico brasileño que necesita ser mencionado. El intento de la ciudad para adaptarse al escenario competitivo global hace que numerosas leyes estén diseñadas para suspender la eficacia de otras leyes, sobre todo las que garantizan los derechos sociales durante la realización de los megaeventos. En Brasil, esto se ha comprobado en la Copa del Mundo en 2014, en la que las leyes temporales suspendían la eficacia de algunas normas, tales como la ley denominada "Estatuto del Seguidor" y la ley del Derecho del Consumidor, y eso cuando no violaban los derechos y garantías previstos en la Constitución, especialmente aquellos que se relacionaban con el derecho a la ciudad.

Compete a la próxima sección demostrar cómo las leyes destinadas a adaptar la ciudad de Río de Janeiro a los Juegos Olímpicos de 2016 representan un poderoso pacto entre el Estado y el sector privado, capaz de imponer un amplio proceso de despojo urbano y segregación socioespacial.

\section{LOS JUEGOS OLÍMPICOS COMO VECTOR DE REVITALIZACIÓN Y DESARROLLO URBANO}

Los Juegos Olímpicos de 1932 son un divisorio en la historia del urbanismo. Hasta entonces, los grandes eventos deportivos dejaban pocas huellas por donde pasaban. Las ciudades no necesitaban cambios significativos para 
Esta revista forma parte del acervo de la Biblioteca Jurídica Virtual del Instituto de Investigaciones Jurídicas de la UNAM

albergar los Juegos. El enfoque recaía en las áreas de la práctica deportiva y nada más. Pero en 1932, la ciudad anfitriona, Los Ángeles, aprovechó la oportunidad para impulsar la economía local y el desarrollo urbano. Una primera Villa Olímpica fue creada con la finalidad de convertirse en vivienda después del evento. Desde entonces, los Juegos Olímpicos se han transformado en un medio de unir el deporte y el desarrollo social, mediante la creación de legados permanentes en las ciudades anfitrionas. ${ }^{13}$

En 1980, con la intensificación de la competencia global, las ciudades adoptaron fórmulas de marketing más agresivas y con el alcance más amplio posible. Una de las más conocidas fue llamada por algunos estudiosos "estrategia de megaeventos". ${ }^{14}$ Así pues, teniendo en cuenta las urgencias contextuales, los Juegos Olímpicos se han convertido en las mayores vedettes de todas las ciudades globales en el mundo. Romeiro y Frota ${ }^{15}$ afirman que: "Después de los años setenta del siglo pasado quedó más evidente la combinación de la organización de eventos deportivos internacionales con los procesos de transformación urbana, acompañada de una política de construcción de infraestructura deportiva como estrategia de renovación urbana".

La ciudad de Barcelona inauguró ese nuevo concepto con ocasión de los Juegos de 1992. No sólo modernizó la infraestructura urbana, sino trató de promover una nueva imagen pública de la ciudad, ${ }^{16}$ en relación con la idea de bienestar, de arquitectura innovadora y de conservación ambiental. La capital catalana se convirtió en una vitrina viva de los numerosos beneficios que los Juegos Olímpicos pueden traer a la sociabilidad y a la economía urbana.

Las ciudades anfitrionas de los Juegos posteriores siguieron los mismos pasos de Barcelona. Al mismo tiempo en que promovieron cambios en las plazas deportivas, llevaron a cabo intensos proyectos de revitalización de

13 Rolnik, Raquel, Relatório sobre megaeventos esportivos e direito à moradia, 2010, disponible en: https: / / raquelrolnik.files.wordpress.com/2010/11/mega_eventos_portugues $1 . p d f$ (fecha de consulta: 15 de diciembre de 2015).

14 Andranovich, Greg et al., "Olympic Cities: Lessons Learned from Mega-Events Politics”, Journal of Urban Affairs, Milwaukee, vol. 23, núm. 2, 2001, p. 114.

15 Romeiro, Paulo y Frota, Henrique Botelho, Megaprojetos de impacto urbano e ambiental: violação de direitos, resistência e possibilidades de defesa das comunidades impactadas, San Pablo, IBDU, 2015, p. 15 (traducción propia).

16 Rolnik, Raquel, op. cit. 
Esta revista forma parte del acervo de la Biblioteca Jurídica Virtual del Instituto de Investigaciones Jurídicas de la UNAM

áreas degradadas, de expansión de las atracciones turísticas y de modernización de la vivienda urbana. Paralelamente, términos como sostenibilidad y legado social se destacan en los discursos emitidos por el COI y por los Estados contratantes.

Pero las consecuencias de los grandes eventos no siempre se pueden categorizar como ventajas. Los beneficios económicos y urbanísticos no están distribuidos de manera uniforme por toda la ciudad, lejos que están de las zonas de mayor interés para la población más socialmente vulnerable. La revitalización de las zonas urbanas se acompaña de desalojo forzoso, de intervenciones urbanas incompletas (porque no siguen una considerable parte de la trama urbana), de limitaciones de derechos mientras se realiza el megaevento. Las imágenes de los Juegos Olímpicos, que se parecen más a los anuncios turísticos, terminan siendo parte de una ideología neoliberal, marcada por la apropiación privada del espacio urbano.

Potenciando el problema, el impacto en los países de la periferia del capitalismo es todavía peor. Está claro que, con la crisis económica mundial, las organizaciones deportivas internacionales han trasladado sus intereses a los países en desarrollo, vinculándose con agentes nacionales, arguyendo que van a promover impactos positivos en las ciudades anfitrionas, ${ }^{17}$ tanto para la infraestructura urbana como para la calidad de vida de la población. Ocurre que en esos países los derechos humanos se violan más fácilmente y un megaproyecto deportivo acaba generando consecuencias catastróficas, principalmente relacionadas con la supresión de viviendas populares que estén obstaculizando la ejecución de los proyectos.

Es importante destacar que los Juegos Olímpicos de Río 2016 tienen la connotación de gesto de apoyo a una ciudad subdesarrollada, pobre, que necesita incentivos para desarrollarse plenamente. Lo que sucede es que, precisamente en nombre de la lucha contra la pobreza, el proyecto olímpico intensifica la pobreza, la marginación, el malestar urbano.

La "estrategia de megaeventos" exacerba muy claramente los papeles de patria, empresa y mercado de que se incumbirá la ciudad. Como consecuencia de ese proceso, las leyes municipales, en lugar de ser expresiones políticas de la organización social, terminan siendo negociadas conforme los juegos de intereses privados.

17 Romeiro, Paulo y Frota, Henrique Botelho, op. cit. 
Esta revista forma parte del acervo de la Biblioteca Jurídica Virtual del Instituto de Investigaciones Jurídicas de la UNAM

\section{LAS LEYES DE EXCEPCIÓN QUE AMPARAN A LA REALIZACIÓN DEL MEGAEVENTO OLÍMPICO}

Como se ha mostrado anteriormente, los Juegos Olímpicos, a pesar de ser sólo un evento deportivo, se han anunciado como una oportunidad de renovación urbana en general para las ciudades anfitrionas. Hay muchos requisitos del COI, desde la construcción de plazas deportivas hasta la renovación de la red de movilidad urbana en las zonas donde se celebran los Juegos, pasando por la implantación de un sistema especial de seguridad y por la realización de reformas estéticas. Al mismo tiempo, una ciudad anfitriona como Río de Janeiro dispone de otros barrios, otras exigencias, otras prioridades que no son soportadas por el proyecto olímpico. Muchas de esas demandas se refieren a la realización de los más esenciales derechos humanos, como la vivienda, la educación, la salud y el saneamiento.

El éxito de un megaevento como los Juegos Olímpicos depende, por lo tanto, de los cambios legislativos que permitan al gobierno llevar a cabo sus segregaciones con un manto de "apoyado por la ley". Estas leyes que apoyan los megaeventos se caracterizan por unos pocos puntos en común: suelen privilegiar el ingreso de actores privados en la preparación y en la realización de los eventos, dándoles ventajas considerables; al mismo tiempo, aseguran que el gobierno realice inversiones por encima de los techos ordinarios y pueden, en nombre de la realización del soñado espectáculo, cerrar espacios temporalmente, expulsar personas de sus hogares y limitar sus inversiones sólo a algunos barrios de la ciudad, entre tantas otras maniobras elitistas y elitizadoras.

Las "leyes olímpicas" son claros ejemplos de distorsión de la ley vigente, en nombre de los intereses económicos de los sectores privados. Se crea lo que Carlos Vainer llama “ciudad de excepción”, verificada de la siguiente manera:

La idea de excepción en el pensamiento político se opone a la de un estado de derecho. Son situaciones excepcionales en las que se suspenden las normas que regulan el estado de derecho, como en las dictaduras y en los regímenes autoritarios. Lo que está ocurriendo hoy en día es que las reglas son establecidas por los intereses casuísticos que benefician solo a algunas y pocas personas. Cuando las 
reglas generales que rigen el funcionamiento y la vida en la ciudad son sometidas a normas excepcionales, surge la ciudad de excepción. ${ }^{18}$

Cabe señalar que el ordenamiento jurídico se construye a través de un complejo sistema legislativo, a partir de la promulgación de una Constitución federal, pasando por las leyes dispersas, siempre elaboradas por representantes de la población que deben, en teoría, legislar en nombre de los valores y hechos que emanan de la sociedad. Cuando, por el contrario, se crean leyes sólo para satisfacer los requisitos de una entidad privada - $\mathrm{e}$ internacional — observamos claramente una lesión en la democracia política y en la soberanía misma de un país.

Después de realizar consideraciones teóricas sobre los efectos de los megaeventos en la política urbana, llega el momento de abordar más específicamente las leyes de excepción creadas en este contexto, apuntando algunas de sus principales modificaciones.

\section{El Acto Olímpico Federal y el Decreto Municipal 30.379/2009}

La Ley Federal núm. 12.035, del 1o. de octubre de 2009, denominada Ley Olímpica, entró en vigor el 2 de octubre de 2009, de validez prevista para finales de 2016, año de realización del megaevento. En esta norma, llama la atención la permisividad ante las actividades del COI y asociados en los espacios públicos, como queda demostrado en el artículo 5o.:

Se permite la cesión de uso de viviendas de propiedad o de tenencia de la Unión o que integren los patrimonios de fondos gestionados por entidades de la administración federal directa o indirecta para las actividades relacionadas con la realización de los Juegos Río 2016, según lo dispuesto por el Poder Ejecutivo. ${ }^{19}$

El artículo 9o., por su parte, determina que: "Se suspenderán durante el período entre el 5 de julio y el 26 de septiembre de 2016 los contratos para

18 Vainer, Carlos B., O Brasil está vivendo um estado de exceção, 2011, p. 2, disponible en: http: / / veja.abril.com.br/noticia/brasil/o-brasil-esta-vivendo-um-estado-de-excecao-diz-urbanista (fecha de consulta: 10 de enero de 2016) (traducción propia).

19 Brasil, op. cit., p. 2 (traducción propia). 
Esta revista forma parte del acervo de la Biblioteca Jurídica Virtual del Instituto de Investigaciones Jurídicas de la UNAM

el uso de espacios publicitarios en los aeropuertos o en las zonas federales de interés de los Juegos de Río 2016, en la forma del reglamento”. ${ }^{20}$

La permisividad se extiende incluso a los servicios públicos, ya que el gobierno federal está obligado a soportar los costes de los servicios médicos y de salud, de la seguridad y de la aduana. Este dispositivo abre así una gran cantidad de posibilidades para la privatización de esos servicios, pues las empresas privadas son contratadas para ejercerlos, como en el caso de las corporaciones de seguridad de Israel contratadas para asegurar la integridad de los atletas y del público.

La protección de la publicidad vinculada al megaevento también es variada y notable. La ley otorga a las autoridades federales el deber de actuar en el control, en la vigilancia y en la represión de actos ilícitos que atenten contra los derechos de los símbolos relacionados con los Juegos Río 2016, tales como banderas, lemas, marcas, nombre, insignias, canciones, mascotas y antorchas —en resumen, cualesquiera palabras o imágenes publicitarias que hagan referencia a una idea de los Juegos Olímpicos, aunque sea indirectamente- .

A su vez, el Decreto Municipal núm. 30.379/2009 también impone regímenes de excepción. El artículo 9o. de dicho documento legal llama la atención. Se prohíbe durante dos meses (que cubren el periodo de los Juegos) que se realicen importantes eventos abiertos al público. ${ }^{21}$ La cuestión es si la interpretación de esa disposición se hará de manera restrictiva, abordando sólo variados eventos deportivos, o si cubrirá la realización de actividades culturales o movilizaciones populares. Debido a que el texto legal no especifica qué actividades realmente se verán restringidas, se espera que el gobierno apunte a eventos de cualquier naturaleza, lo que se caracteriza como un asalto a la democratización del espacio público y a la posibilidad de manifestación cultural y política.

El mismo decreto proporciona amplia posibilidad para que el COI y los demás apoyadores del megaevento utilicen los bienes pertenecientes al gobierno municipal, aunque ocupados por terceros. Es lo que se demuestra con la lectura del artículo 2o. del decreto:

20 Ibidem, p. 3 (traducción propia).

21 Río de Janeiro (Municipio), op. cit. 
El Poder Ejecutivo hará todos los esfuerzos necesarios con el fin de posibilitar el uso de los bienes pertenecientes a la administración pública municipal, aunque ocupados por terceros, esenciales para los Juegos Rio 2016.

Párrafo único - Cualquier acto de concesión, permiso o autorización de uso de las propiedades a las que se refieren el caput de este artículo deberán contener cláusula que prevea la entrega a la Municipalidad de Río de Janeiro, a tiempo de implementar los ajustes necesarios para la realización de los Juegos Río 2016. ${ }^{22}$

Aún más grave es la disposición del artículo 12, ya que abre la posibilidad de lesiones a los derechos fundamentales, si la realización y la protección de estos son un obstáculo para la construcción del proyecto olímpico. La línea I dispone que la municipalidad debe “...promover expropiaciones y otras medidas indispensables para la construcción de instalaciones deportivas y no deportivas...". ${ }^{23}$

Este trabajo no se vuelve en contra el instituto jurídico de la expropiación en sí misma, la cual es un inductor importante del desarrollo urbano, cuando se aplica correctamente. Lo que llama la atención sobre el presente caso es que la expulsión de personas de sus hogares puede ocurrir por la realización de un evento transitorio, que promueve una serie de propuestas de desarrollo guiadas no por las necesidades de la ciudad en su conjunto, pero sólo por áreas restringidas que serán anfitrionas de las actividades deportivas. El derecho a la vivienda, una de las bases de la realización de la dignidad humana, termina sometiéndose a los paradigmas privados de desarrollo urbano.

Por último, también en el artículo 12 del Decreto, hay un dispositivo que obliga al gobierno municipal a reservar recursos presupuestarios para cubrir los gastos con las actividades previstas. En este caso, las actividades previstas no se refieren a una reestructuración urbana general, sino en unos pocos lugares en Río de Janeiro, y no guardan relación con mejora en los ámbitos del saneamiento, de la atención a la salud y de la educación. Generalmente se limitan a la seguridad pública, a la movilidad urbana y a las recalificaciones generales en unas pocas zonas de la ciudad, normalmente ubicadas en los barrios más nobles o en lugares con gran viabilidad para convertirse en barrios nobles en un futuro próximo.

22 Ibidem, pp. 2 y 3 (traducción propia).

23 Ibidem, p. 7 (traducción propia). 
Esta revista forma parte del acervo de la Biblioteca Jurídica Virtual del Instituto de Investigaciones Jurídicas de la UNAM www.juridicas.unam.mx

Es importante tener en cuenta que existen otros documentos legales creados para proteger los intereses del COI. Un claro ejemplo es el Acto Olímpico del Estado de Río de Janeiro, ${ }^{24}$ que no es una ley en el sentido estricto de la palabra, porque es un decreto redactado por el Ejecutivo de la ciudad. La característica más notable de dicha ley es que puede potenciar los efectos de las leyes ya mencionadas, así como extenderlos más allá de los límites de la capital.

Entre sus disposiciones más controvertidas, el Acto Olímpico del Estado de Río de Janeiro, en el artículo 13, determina que la prohibición de llevar a cabo otros eventos importantes (no sólo los deportivos, sino artísticos y culturales) es válida en toda la región metropolitana de Río, lo que implica 21 municipios. Dicho Acto aún incluye una serie de medidas para garantizar la viabilidad fiscal del megaevento deportivo, entre los cuales se destacan la protección a los símbolos y a la publicidad promovidos por el COI, la obligación de prever los gastos necesarios a los juegos en las leyes presupuestarias del Estado y la posibilidad de transferencia temporal de edificios gubernamentales a los organizadores del evento.

Otro aspecto del problema, que ilustra el alcance de los intereses de los actores privilegiados en el escenario, es que la preparación de las leyes de excepción no se limita a la ciudad anfitriona o a sus alrededores. Debido a que algunas de las modalidades deportivas de los Juegos Olímpicos se celebrarán en ciudades de diferentes regiones del país - como Salvador, San Pablo y Manaos, anfitrionas de los partidos de fútbol- esas ciudades auxiliares terminan siendo objeto de nuevas negociaciones entre el COI, el gobierno local y los actores sociales que pertenecen a las minorías hegemónicas.

Un claro ejemplo de ello son los términos de cooperación firmados entre el Comité Organizador de los Juegos y el gobierno de esas ciudades secundarias, que garantizan muchas prerrogativas al COI y a sus patrocinadores. En el caso de San Pablo, ${ }^{25}$ por ejemplo, el término firmado cubre las

24 Rio de Janeiro (Estado), Decreto no. 41.839 de 29 de abril de 2009. Dispõe sobre medidas a serem adotadas pelo Estado do Rio de Janeiro para a realização dos Jogos Olímpicos e Paraolímpicos Rio 2016, na cidade do Rio de Janeiro, 2009, disponible en: http: / / www.ioerj.com.br/portal/modules/ conteudoonline $/$ view_pdf.php?ie. $=\mathrm{NTk} 0 \mathrm{Ng}==\& \mathrm{ip}=\mathrm{MQ}==\& \mathrm{~s}=\mathrm{M} 2 \mathrm{Q} 3 \mathrm{MGQ} 4 \mathrm{MTZiMGIyOT}-$ M4ODE1YWQ5YzU3OWJiNTMzOWM= (fecha de consulta: 21 de diciembre de 2015).

25 San Pablo (Município), Termo de Cooperação entre o Comitê Organizador Rio 2016 e a Prefeitura de San Pablo, 2015, disponible en: http://www.prefeitura.sp.gov.br/cidade/secretarias/ 
restricciones de publicidad en todo el perímetro de la ciudad, las restricciones a la realización de otros megaeventos y los beneficios para la contratación de trabajadores, entre otros provechos que garanticen la realización (y la rentabilidad) de los Juegos.

Los documentos legales citados también aseguran exenciones tributarias para el COI y para las empresas relacionadas con sus intereses, elevan el límite de la deuda de la ciudad de Río de Janeiro hacia la realización del megaevento y se unen a otros textos legales para permitir sistemas de contratación diferenciados. ${ }^{26}$ Estas normas, como se puede ver, son "leyes ilegales", ya que no se armonizan con varios preceptos del ordenamiento jurídico brasileño, tales como los que aseguran los derechos fundamentales, como la vivienda, la dignidad humana, la supremacía y la indisponibilidad del interés público, etcétera. La ciudad-empresa, en nombre de hacer un buen negocio, deja de lado sus leyes y favorece demasiado los deseos no sólo del COI y de sus patrocinadores, sino también de una serie de sectores privados que se benefician de la elitización de la ciudad.

\section{LEGADO ¿PARA QUIÉN? FORMULANDO CONSIDERACIONES FINALES}

Un análisis más detallado de la propuesta de reestructuración urbana vinculada al proyecto de los Juegos Olímpicos de 2016 apunta hacia la sumisión de la política pública a los intereses privados, sobre todo en los sectores inmobiliario, financiero y turístico. ${ }^{27} \mathrm{Al}$ mismo tiempo, las clases con menos recursos son vistas como antagonistas del proceso de crecimiento económico de la ciudad y son consideradas enemigas desde el momento de la redacción de las leyes hasta las etapas de remoción de estas poblaciones de los espacios públicos, hasta de sus propios hogares.

Los procesos de expropiación, desde esa óptica, terminan siendo herramientas no para hacer efectivos los intereses públicos centrados en el

upload/governo/arquivos/Acordos/Cooperacao_Rio2016_1.pdf (fecha de consulta: 21 de diciembre de 2015).

26 Vainer, Carlos B., Com leis próprias, megaeventos criam Estado de exceção, 2013, disponible en: http://apublica.org/2013/01/copa-do-mundo-olimpiadas-leis-estado-de-excecao/ (fecha de consulta: 13 de diciembre de 2015).

27 Castro, Demian et al., op. cit. 
Esta revista forma parte del acervo de la Biblioteca Jurídica Virtual del Instituto de Investigaciones Jurídicas de la UNAM

desarrollo armonioso de la ciudad, sino por el contrario, para la apertura de nuevas fronteras para la explotación del capital privado. La población pobre en las zonas que se han valorizado en los últimos tiempos o que tienen posibilidad de convertirse en un buen negocio, por lo tanto, terminan siendo expulsados de estos corredores de nuevas oportunidades para el sector inmobiliario.

No es casualidad que las intervenciones propuestas por el proyecto olímpico recaigan casi exclusivamente en la Zona Sur y Barra da Tijuca (las principales zonas con gran potencial de acumulación de activos financieros), y la zona portuaria (zona infravalorada, pero con la perspectiva de un buen negocio futuro vinculado a la remoción de la población residente en este local). Las clases vulnerables que se encuentran en esos lugares y son afectadas por la segregación en las políticas públicas, así como las personas que viven fuera del eje de grandes transformaciones, sufren porque no han sido protegidas por las grandiosas inversiones, valoradas en muchos miles de millones de reales y sólo aplicadas a una pequeña parte del municipio.

Las leyes creadas para salvaguardar el proyecto olímpico son un atentado a los derechos fundamentales de la población fluminense. Las múltiples dimensiones del derecho a la ciudad, derecho humano que agrega otros tantos bienes jurídicos de gran importancia para la dignidad de los habitantes, no sólo deben preservarse durante la preparación y la realización de los megaeventos, también deben guiar la elaboración de leyes y de políticas públicas.

El Acto Olímpico y el Decreto núm. 30.379/2009, por otra parte, son normas que impiden el usufructo equitativo de las ciudades y violan valores importantísimos de sostenibilidad, de democracia y de justicia social. Los habitantes de Río de Janeiro no participaron en la elaboración de las normas, a pesar de que ellas regulen el uso y el disfrute de la ciudad de forma significativa.

Con su atención centrada en la elevación del valor de intercambio de los espacios urbanos impactados por el proyecto olímpico, los planificadores urbanos impiden que las comunidades más desvalidas utilicen y permanezcan en esos lugares. Es sabido que la valoración inmobiliaria suele representar una gran amenaza contra el mantenimiento y la fijación de las personas de bajos ingresos dentro o en los alrededores de los gran- 
Esta revista forma parte del acervo de la Biblioteca Jurídica Virtual del Instituto de Investigaciones Jurídicas de la UNAM

des emprendimientos; ${ }^{28}$ el valor de uso, por lo tanto, debe priorizarse, mientras el valor de intercambio debe sufrir riguroso control. Para Raquel Rolnik: ${ }^{29}$

...altos estándares y normas de planificación urbana pueden subir los precios del suelo, lo que hace difícil —o imposible — el acceso de los pobres a la vivienda y al suelo urbano... [La planificación y la regulación urbanas están] totalmente construidas bajo la lógica económica y adaptadas a los ritmos del mercado, especialmente los de las empresas promotoras inmobiliarias y de inversiones para los sectores con mayores ingresos. La legislación urbanística sirve básicamente para definirles y reservarles las mejores zonas, evitando la "invasión" por los pobres.

Las "leyes olímpicas de excepción" todavía se caracterizan por presentar claramente instrumentos jurídicos favorables a los sectores privados que organizan el evento, los cuales encuentran en el proyecto olímpico una oportunidad única para beneficiarse a costa de los impuestos y de sacrificios de toda la población. Al final del megaevento, una serie de proyectos serán administrados por el sector privado, tales como hoteles, centros deportivos, centros culturales, etcétera. En lo relativo al impacto urbano en general, sólo tres regiones urbanas resultarán beneficiadas, mientras que la mayor parte de la municipalidad quedará desamparada, recibiendo las miles de personas que fueron retirados de las áreas olímpicas. Para empeorar las cosas, todavía no existe recalificación urbana en las proximidades de las zonas olvidadas.

No cabe duda que el legado olímpico, en términos generales, apunta a los sectores inmobiliario, financiero y turístico. El derecho a la ciudad, como derecho fundamental conectado a tantos otros, resulta suprimido,

28 "Llama la atención, por lo tanto, que la mayoría de las remociones se encuentren en áreas de extrema valoración inmobiliaria. En los últimos tres años [2012-2015], el precio del metro cuadrado de las propiedades vendidas en la ciudad de Río de Janeiro aumentó en promedio unos 29,4\%, pero en algunas zonas, como en la favela de Vidigal, la valoración es tan alta como 481,0\%" (Observatório das Metrópoles, Rio 2016: os jogos da exclusão, 2015, p. 1, disponible en: http:// observatoriodasmetropoles.net/index.php?option $=$ com_k2\&view=item\& id $=1416 \% 3$ Alan $\%$ C 3\%A7ametno-dossi $\%$ C $3 \% A A$-megaeventos-e-viola $\%$ C3\%A7\%C3\%B5es-dosdireitos-humanos-no-rio\&Itemid=164 (fecha de consulta: 15 de febrero de 2015) (traducción propia).

29 Rolnik, Raquel, Guerra dos lugares: a colonização da terra e da moradia na era das finanças, San Pablo, Boitempo, 2015, p. 40 (traducción propia). 
Esta revista forma parte del acervo de la Biblioteca Jurídica Virtual del Instituto de Investigaciones Jurídicas de la UNAM

abdicado en nombre de un crecimiento del poder financiero privado, lo cual no tiene relación con el desarrollo económico y social sostenible, con la preservación ambiental y mucho menos con la justicia social.

Es difícil establecer caminos para la reversión de esta situación tan grave señalada en un escenario de competición internacional tan feroz, en el que el discurso de crisis alimenta la necesidad de que las autoridades locales se comporten como empresas y no como gobiernos. A pesar de todo, dos vías pueden ser emprendidas para que la ciudad entre en el contexto globalizado sin poner en peligro la seguridad de su población y su sostenibilidad.

El primer modo de resolución se refiere a la necesidad de establecer canales de relación entre los sectores público y privado y entre las empresas y la población, para que la continuidad de la comunicación sensibilice las distintas partes implicadas en el proceso de producción del espacio urbano. La realidad práctica no ha mostrado buenos ejemplos de esos canales de articulación; sin embargo, desde el momento en que más personas se responsabilizan de su ciudad, es posible que la política vuelva a ser la fuerza motora de la armonización social y del desarrollo urbano sostenible. De ese modo, la llegada de un megaevento se llevaría a cabo en un entorno marcado por la transparencia en las relaciones y no por la aplicación de la idea de crisis urbana que se necesita superar de cualquier manera, incluso costando vidas humanas.

Por último, para evitar los efectos nocivos del feroz combate entre diferentes ciudades, es necesario crear organismos reguladores locales, regionales, nacionales e incluso internacionales, responsables de la aplicación de las normas mínimas para el juego, previniendo que las ciudades que reciban los megaeventos vendan sus espacios y su gente para la celebración de los Juegos. Según Somekh y Campos Neto: ${ }^{30}$ "El ejemplo europeo, donde el punto de vista estratégico coexiste con un alto grado de intervencionismo y con la multiplicación de iniciativas gubernamentales estructuradoras, compensatorias y reglamentarias, merece una atención especial en ese sentido”.

El Río olímpico demuestra ser objeto de una legislación urbanística de excepción que materializa las políticas de exclusión, marcadas por la rentabilidad para los grupos hegemónicos. Tales debilidades ya se comprueban

30 Somekh, Nadia y Campos Neto, Candido Malta, Desenvolvimento local e projetos urbanos, 2005, p. 1, disponible en: http://www.vitruvius.com.br/revistas/read/arquitextos/05.059/470 (fecha de consulta: 30 de enero de 2016) (traducción propia). 
en la capital carioca desde hace tiempo, y sólo se han intensificado con la preparación para el megaevento deportivo de 2016. De hecho, las supresiones al derecho a la ciudad transcurridas con el proyecto olímpico no deben ser vistas como algo temporal, algo que se limita a la realización de un espectáculo, y que termina después de ello. Se trata de un proceso dinámico de expoliación urbana que necesita ser mejor entendido en este momento en el que se hace más visible, por lo que más tarde pueda ser combatido.

\section{BIBLIOGRAFÍA}

Andranovich, Greg et al., "Olympic Cities: Lessons Learned from MegaEvents Politics”, Journal of Urban Affairs, Milwaukee, vol. 23, núm. 2, 2001.

BRASIL, Lei no. 12.035, de 1o. de outubro de 2009. Institui o Ato Olímpico, no âmbito da administração pública federal, com a finalidade de assegurar garantias à candidatura da cidade do Rio de Janeiro a sede dos Jogos Olímpicos e Paraolímpicos de 2016 e de estabelecer regras especiais para a sua realização, condicionada a aplicação desta Lei à confirmação da escolha da referida cidade pelo Comitê Olímpico Internacional, 2009, disponible en: http: / /www.planalto.gov.br/ ccivil_03/_ato2007-2010/2009/lei/112035.htm (fecha de consulta: 15 de diciembre de 2015).

Castro, Demian et al., "O Projeto Olímpico da Cidade do Rio de Janeiro: reflexões sobre os impactos dos megaeventos esportivos na perspectiva do direito à cidade", en SANTOS Junior, Orlando et al., Brasil: os impactos da Copa do Mundo 2014 e das Olimpíadas 2016, E-papers, Río de Janeiro, 2015.

Comité Popular de la Copa y de los Juegos Olímpicos en Río de JANEIRO, Megaeventos e violações dos direitos humanos no Rio de Janeiro, 2015, disponible en: https: / / br.boell.org/sites/default/files/dossiecomiterio 2015_-_portugues.pdf (fecha de consulta: 15 de febrero de 2016).

GlobAL Brasil, Remoções forçadas para Copa e Olimpíadas no Brasil serão tratadas em sessão do Conselho de Direitos Humanos da ONU, 2013, disponible en: http: / / global.org.br/programas/remocoes-forcadas-para-copa-e-olimpiadas- 
Esta revista forma parte del acervo de la Biblioteca Jurídica Virtual del Instituto de Investigaciones Jurídicas de la UNAM

no-brasil-serao-tratadas-em-sessao-do-conselho-de-direitos-humanos-da-onu/ (fecha de consulta: 15 de febrero de 2016).

LeFebvre, Henry, El derecho a la ciudad, Barcelona, Península, 1978. , O direito à cidade, San Pablo, Centauro, 2001.

ObSERVATÓRIO DAS MeTrÓPOles, Rio 2016: os jogos da exclusão, 2015, disponible en: http: / / observatoriodasmetropoles.net/index.php?option $=$ com_k2 \&view $=$ item\&id $=141 \% 3$ Alan $\%$ C 3\%A7ametno-dossi $\%$ C 3\%AA-megaeventos-eola $\%$ C 3\%A7\%C3\%B5es-dos-direitos-humanos-no-rio\&Itemid $=164$ (fecha de consulta: 15 de febrero de 2015).

OliveIRA, Nelma G., Força de Lei: rupturas e realinhamentos institucionais na busca do "sonho olímpico" carioca, Actas del XIV Encontro Nacional da ANPUR, Río de Janeiro, 2011.

Rio De Janeiro (Estado), Decreto no. 41.839 de 29 de abril de 2009. Dispõe sobre medidas a serem adotadas pelo Estado do Rio de Janeiro para a realização dos Jogos Olímpicos e Paraolímpicos Rio 2016, na cidade do Rio de Janeiro, 2009, disponible en: http://www.ioerj.com.br/portal/modules/conteudoon line / view_pdf.php?ie $=N T k O N g==\& i p=M Q==\& s=M 2 Q 3 M G Q 4 M T Z i M G I$ yOTM4ODE 1 YWQ5YzU3OWJiNTMzOWM = (fecha de consulta: 21 de diciembre de 2015).

Río De Janeiro (Municipio), Decreto no. 30.379, de $1^{\circ}$ de janeiro de 2009. Dispõe sobre medidas a serem adotadas pelo Município do Rio de Janeiro para a realização dos Jogos Olímpicos e Paraolímpicos Rio 2016, na cidade do Rio de Janeiro, 2009, disponible en: http: / /wpro.rio.rj.gov.br/decretosmunicipais / (fecha de consulota: 21 de diciembre de 2015).

ROLNIK, Raquel, A cidade e a lei: legislação, política urbana e territórios na cidade de San Pablo, San Pablo, Studio Nobel-Fapesp, 1997.

, Guerra dos lugares: a colonização da terra e da moradia na era das finanças, San Pablo, Boitempo, 2015.

- Relatório sobre megaeventos esportivos e direito à moradia, 2010, disponible en: https://raquelrolnik.files.wordpress.com/2010/11/mega_eventos_ portugues1.pdf (fecha de consulta: 15 de diciembre de 2015).

RomeIro, Paulo y Frota, Henrique Botelho, Megaprojetos de impacto urbano e ambiental: violação de direitos, resistência e possibilidades de defesa das comunidades impactadas, San Pablo, IBDU, 2015.

SAn Pablo (Municipio), Termo de Cooperação entre o Comitê Organizador Rio 2016 e a Prefeitura de San Pablo, 2015, disponible en: http: / / www.prefeitura.sp.gov.br/cidade/s 
ECRETARIAS / UPLOAD / GOVERNO / ARQUIVOS / ACORDOS / COOPERACAO_RIO2016_1. PDF (fecha de consulta: 21 de diciembre de 2015).

SomeKh, Nadia y CAmpos Neto, Candido Malta, Desenvolvimento local e projetos urbanos, 2005, disponible en: http: / / www. vitruvius.com.br/revistas / read/arquitextos/05.059/470 (fecha de consulta: 30 de enero de 2016).

VAIner, Carlos B., Com leis próprias, megaeventos criam Estado de exceção, 2013, disponible en: http://apublica.org/2013/01/copa-do-mundo-olimpiadasleis-estado-de-excecao/ (fecha de consulta: 13 de diciembre de 2015).

, "Pátria, empresa e mercado", en ArAnTes, Otília et al., A cidade do pensamento único: desmanchando consensos, Petrópolis, Vozes, 2001.

, O Brasil está vivendo um estado de exceção, 2011, disponible en: http: / / veja.abril.com.br/noticia/brasil/o-brasil-esta-vivendo-um-estado-deexcecao-diz-urbanista (fecha de consulta: 10 de enero de 2016). 